\title{
Origens, Desenvolvimento e Panorama Actual da Bioquímica da Faculdade de Ciências da Universidade de Lisboa
}

\author{
R, E.PINTO *, I, A MARAL * *
}

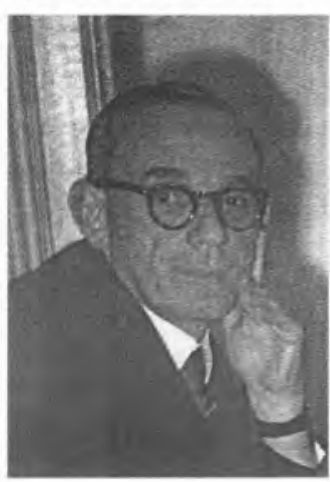

"Trabalhar em Bioquímica é decifrar os segredos mais misteriosos da natureza pelos recursos da inteligência humana; passaram contudo os tempos, em que o sábio, meditando no seu gabinete, resolvia de olhos fechados o problema eterno da vida. O investigador actual já não adivinha enigmas nem argumenta com a própria autoridade e a dignidade dos seus antecessores... não basta penetrar como anatómico no labirinto do corpo animal, nem herborizar como um botânico, para se fazer ideia das reacções químicas complicadíssimas que se dão nas células...

K. Jacobsohn, Conferências IRC, 1934

\section{INTRODUÇÃO: OS PRIMÓRDIOS DA BIOQUÍMICA}

Falar da evolução da Ciência em geral, é tratar das descobertas fundamentais, do amadurecimento das ideias e dos arquitectos que meticulosamente edificaram esta fabulosa catedral, este complexo edifício que Hans Adolph Krebs (1900-1981) tanto valorizava. Não iremos fazer uma análise descritiva da História da Bioquímica, mas apenas dar a conhecer o esqueleto conceptual das princi- pais contribuições feitas até K. Jacobsohn vir para Portugal e, principalmente, as que de alguma forma se intersectam com a realidade portuguesa, em particular com a Faculdade de Ciências da Universidade de Lisboa.

A Bioquímica surgiu como disciplina independente no início do Séc. XX. As primeiras tentativas de emancipação da Química Fisiológica, a disciplina precursora da Bioquímica, foram feitas na Alemanhal a partir da Fisiologia e Química Orgânica, sendo os primeiros trabalhos publicados por volta de 1850 .

Todavia, as preocupações por aspectos hoje considerados bioquímicos, perdem-se um pouco na origem dos tempos. Podemos delimitar os primeiros trabalhos com Theophrastus Bombastus von Hohenheim (1493-1541), mais conhecido como Paracelso. A união da Química de Paracelso com a Medicina e a Biologia, a Iatroquímica, despertou o interesse pelo estudo da vida com base na Química da época. Foram necessários cerca de 250 anos para que a Química surgisse como Ciência. Carl Wilhelm Scheele (1742-1786) e Antoine Lavoisier (1743-1794) foram iniciadores desse processo e são considerados como fundamentais para o estabelecimento das raízes do que viria a ser a Bioquímica. Scheele descobriu vários compostos existentes nos seres vivos, ou produzidos por estes (Química Orgânica) além de ter descoberto vários elementos químicos. Lavoisier verificou a lei da conservação da matéria, foi protagonista da nova nomenclatura química e da racionalização da própria Química, além de outras contribuições fundamentais na História da Químicall. As suas contribuições foram fulcrais para a emergência da Química FisiológicaIII. A evolução natural da investigação química conduziu ao desenvolvimento dos fundamentos da Química científica, com o aparecimento e utilização de técnicas de análise elementar quantitativa protagonizadas pelos trabalhos de Jöns Jacob Berzelio (1779-1884) e de Justus von Liebig (1803-1873). O primeiro introduziu também o con- ceito de catálise, que foi crucial na Bioquímica, entendida como química catalítica, ou seja, enzimática.

Após ter sido sintetizada a ureia, por R. Wöhler (1800-1882), em 1828 , muitos foram os compostos biológicos sintetizados no laboratório. M. Berthelot (1827-1907) foi importantíssimo neste âmbito da investigação científica sintetizando alguns deles cuja existência não era conhecida nos organismos vivos. Este facto conduziu Kékulé a separar a Química Orgânica em Química dos Compostos de Carbono e em Química Fisiológica. Emil Fischer (1852-1919), já no último quartel do século passado, dedicou-se à investigação da estrutura e da síntese das oses assim como da estrutura das proteínas, que mostrou ser peptídica. Foi um passo gigantesco na construção da Bioquímica, no sentido da Bioquímica Estática (Química dos organismos vivos).

A origem da Bioquímica devese não só ao desenvolvimento da Química como da Biologia, e, também da Física. Com o aparecimento da teoria celular de Schleiden (1804$1881)$ e Schwann (1810-1882) começou a acreditar-se que só nas células poderiam ocorrer as reacções biológicas (vitalismo). Louis Pasteur (1822-1895) teve grande importância na aceitação destas ideias devido aos estudos de fermentação e à criação da Microbiologia. Além disto, deve-se também a Pasteur a separação de estereo-isómeros ópticos e o facto de se ter apercebido de que "a vida é função da dissimetria molecular"IV. Rudolf Virchow (1821-1902), um dos maiores biólogos de sempre, associou a teoria celular à patologia dando origem à sua grande obra, a teoria da Patologia Celular.

Em 1897, o vitalismo tende a desaparecer devido à contribuição de Eduard Büchner (1860-1917). ao observar que era possível obter um extracto enzimático das células de levedura, a zimase, responsável pela fermentação alcoólicav. Esta descoberta foi considerada uma das mais poderosas ferramentas da Bioquímica: a possibilidade de tornar viável o estudo químico experimental 
dos sistemas metabólicos altamente complexos que ocorrem nas células. Na realidade é, em geral, aceite que tenha nascido assim a Bioquímica.

Nove anos após a descoberta de Büchner, foi possível a Arthur Harden (1865-1940) e W.J.Young, em Cambridge, observarem que para a fermentação não são só necessárias enzimas mas também fosfato e um co-factor termostável de baixo peso molecular a que se chamou cozimase. Mais tarde Otto Meyerhoff (1884-1951) observou que este mesmo composto era necessário na glicólise muscular mostrando assim que existe muito maior semelhança dos processos metabólicos na matéria viva do que se julgava.

O estudo da fermentação alcoólica foi essencial (e iniciador) no conhecimento da existência e dos mecanismos de produção dos diferentes compostos intermediários a partir da glucose, em condições de anaerobiose. Vamos encontrar como protagonista fundamental desta linha de investigação, Carl Alexander Neuberg (1877-1956) $\mathrm{VI}$, que descobriu ser o fosfato de frutose (ester de Neuberg) um composto intermediário na fermentação da glucose pela levedura. Descobriu, ainda, o conjunto dé reacções intermediárias da sequência da degradação dos glícidos que constituem as reaç̧ões típicas da fermentação alcoólica: o piruvato é descarboxilado produzindo aldeído acético que é depois reduzido a álcool etílico. Prosseguindo a investigação sobre fermentações, propôs outros tipos de mecanismos entre os quais, o que conduz á formação de glicerol. Esta descoberta foi de grande importância para a Alemanha quando houve falta de gorduras (glicéridos) para a produção de glicerol.

Por outro lado a descoberta feita em Cambridge, por Frederick Gowland Hopkins (1861-1947) - que mostrou a redução do piruvato a lactato, durante a contracção muscular. conduziu à reacção típica da glicólise, pois não existe na fermentação alcoólica.

Ao interesse pela investigação dos processos anaeróbios seguiu-se, naturalmente, o interesse pelos processos aeróbios, que marcaram o período áureo do desenvolvimento da Bioquímica nos anos 30 centralizada de início na Alemanha e depois em Inglaterra e no resto da Europa.

Otto Heinrich Warburg (18831970), discípulo de E. Fischer, foi provavelmente o maior de todos os bioquímicos pela sua vasta cultura científica e técnica que lhe permitiu uma versatilidade ímpar como investigador. A sua obra é extraordinária não só pela qualidade e quantidade, como pelas várias áreas investigadas e desenvolvidas VII. Estão neste caso, ainda antes dos anos trinta, a criação e aperfeiçoamento das metodologias e técnicas como a manometria, a espectrofotometria e a técnica de "fatias de tecidos"; as descobertas fundamentais sobre os tumores cancerosos (glicólise aeróbia) e ainda, as primeiras e mais importantes descobertas na oxidação aeróbia, como por exemplo, a descoberta do Atmungsfer. ment (enzima respiratório), hoje conhecido por citocromo oxidase. Foi precisamente pelos estudos realizados entre 1926 e os finais dos anos vinte sobre o enzima respiratório que Warburg foi galardoado com o Prémio Nobel de Medicina e Fisiologia de 1931.

Por volta de 1929, Kurt P. Jacobsohn chegou a Portugal. Também nesse ano, H. A. Krebs se doutorava com O. Warburg, em Berlim. Krebs estudou no laboratório de Warburg o efeito dos metais pesados e heminas como catalisadores de processos oxidantes (oxidação da cisteína, por exemplo) envolvendose pois na investigação do metabolismo aeróbio. Durante os anos trinta foi responsável pela concepção e descoberta dos ciclos biológicos degradativos (ciclo da ornitina, ciclo do ácido cítrico ou de Krebs e ciclo do glioxilato). Pela descoberta do ciclo fundamental do metabolismo aeróbio, foi-lhe atribuído o Prémio Nobel em 1953 e o título de cavaleiro em 1956, passando a ser conhecido por Sir Hans KrebsviII. Embora a versão original deste ciclo tivesse sido alterada ao longo do tempo devido à descoberta de novos compostos intermediários, ela representa uma ideia de perfeição e de economia termodinâmica dos sistemas biológicos, ideia única na História da Bioquímica. Além disto mostra como se forma o dióxido de carbono (produto final carbonado da degradação aeróbia) e o potencial redutor usado na cadeia transportadora de electrões, tendo como produto final, água, que representa o processo terminal na oxidação dos alimentos.

Em Portugal, K. Jacobsohn desenvolveu a sua investigação sobre várias reacções do ciclo de Krebs, em particular, a reacção catalisada pela fumarase. Alguns estudos efectuados sobre este enzima, ainda hoje são reconhecidos como excelentes atendendo ao equipamento laboratorial disponível na altura.

Tentou-se desta forma dar a conhecer a sequência do essencial descoberto na Bioquímica até à vinda de Kurt P. Jacobsohn para Portugal, e dos investigadores que directa ou indirectamente estão na origem da $\mathrm{Bi}$ oquímica do nosso País, em particular, da Faculdade de Ciências da Universidade de Lisboa.

\section{ORIGENS DA INVESTIGAÇÃO DA BIOQUÍMICA EM PORTUGAL E DA FACULDADE DE CIÊNCIAS DA UNIVERSIDADE DE LISBOA}

"If Scientists never change their minds, they eventually die "M. Planck

Em 1911 são extintas a Escola Médico-Cirúrgica e a Escola Politécnica sendo substituídas pelas Faculdades de Medicina e de Ciências. Estas Faculdades apresentam uma estratégia em alguns aspectos diferentes das Escolas que vieram substituir, sendo a mais importante, o papel que a componente experimental passou a desempenhar no ensino da Química Fisiológica, e que foi determinante na formação de uma mentalidade científica, permitindo assim o desenvolvimento de um es- 
pírito mais dirigido no sentido da investigação.

As condições para o desenvolvimento da investigação eram muito pobres não só do ponto de vista laboratorial, como humano. Não existia praticamente ninguém que tivesse preparação experimental nem hábitos de investigação científica $e$, não havia, portanto, incentivo à investigação nem ao apetrechamento dos laboratórios. Parece razoável considerar-se que toda esta situação se alterou pela vinda de Marck Anahory Athias (1875-1946) para Lisboa. Athias era licenciado em Medicina pela escola francesa onde privou com ilustres cientistas que muito contribuíram para a sua revelação como homem de ciênciaIX. Marck Athias poderá ser considerado pioneiro, em Portugal, da aplicação prática do método experimental e consequente incentivo à investigação laboratorial na Medicina, em particular, na Faculdade. Além disso não deve ser esquecida a sua grande contribuição no desenvolvimento do espírito crítico relativo à produção científica nacional bem como da sua divulgação $x$. Toda a sua postura científica e metodologia de trabalho conduziu à formação de alguns discípulos fieis aos seus princípios e capazes de darem continuidade a um projecto de investigação em diferentes áreas da biomedicina. Do conjunto de seguidores que teve destacamse, Celestino da Costa, Joaquim Fontes e muito particularmente, Ferreira de Mira.

Em Portugal a investigação em Bioquímica, foi implantada em 1929 XI com a vinda de Kurt Jacobsohn de Berlim, onde trabalhou e se doutorou com Carl Neuberg, o grande químico orgânico e bioquímico a quem se deve uma obra grandiosa e ainda, a vulgarização do termo BioquímicaXII. Kurt Jacobsohn veio para Lisboa por iniciativa de Ferreira de MiraXIII, professor de Química Fisiológica da Faculdade de Medicina da Universidade de Lisboa, fundador e primeiro director do Instituto de Investigação Científica Bento da Rocha Cabralxıv.
Ferreira de Mira sendo um cientista de visão dinâmica da Ciência cedo reconheceu que a Bioquímica era uma disciplina muito importante que embora já não estivesse a dar os primeiros passos a nível mundial, ainda não existia em Portugal. Conhecendo bem os trabalhos de Carl Neuberg no âmbito da Química Orgânica em que era exímio, deslocou-se a Berlim e pediu-lhe que lhe sugerisse um dos seus assistentes para liderar a secção de Química Biológica do IRC. Neuberg indicou-lhe Kurt Jacobsohn que chegou recém doutorado a Lisboa, em 1929. Quatro anos depois Ferreira de Mira estabeleceu com ele um contrato que se tornou vitalício tendo-se tornado então o único bioquímico no IRC e em Portugal.

Kurt Jacobsohn continuou em Portugal uma actividade científica vocacionada para o estudo do metabolismo e para a enzimologia. Em 1935 depois de the ter sido atribuída a equiparação do grau de Doutor, pela Universidade de Berlim ao de Doutor em Ciências Físico-Químicas da Universidade de Lisboa, ingressou na carreira universitária na Faculdade de Ciências, onde permaneceu quarenta anos. Assim deu início à investigação e ensino da Bioquímica da Faculdade de Ciências da Universidade de LisboaXv.

\section{DESENVOLVIMENTO DA BIOQUÍMICA DA FACULDADE DE CIÊNCIAS DA UNIVERSIDADE DE LISBOA}

A presença de Kurt Jacobsohn na Faculdade de Ciências da Universidade de Lisboa e o início do ensino da Bioquímica na Disciplina de Química Orgânica estimulou o interesse de alguns estudantes nesta disciplina. Deodata de Azevedo foi o primeiro aluno a seguir esse caminho e a fazer estágio de investigação de licenciatura em Físico-Química com o Prof. Jacobsohn tendo dedicado toda a sua vida profissional a esta área científica. Depois de licenciada foi para o IRC onde se manteve trabalhando com Kurt Jacobsohn até final da vida científica deste, continuando depois até se reformar.

Outros estudantes vieram a interessar-se também pela Bioquímica tendo dois deles vindo a ser docentes da Secção de Química e a fazerem doutoramentos em assuntos de carácter bioquímico, Ruy $\mathrm{E}$. Carvalho Pinto (R. E. Pinto) e Renato Leal. O primeiro destes fez o estágio de investigação com Kurt Jacobsohn na Faculdade e no IRC, entre $1951 \mathrm{e}$ 1953. No ano lectivo de $1956 / 57$ esteve na Universidade de Oxford onde fez um curso de pós-graduação em Bioquímica sob a supervisão de Sir Hans Krebs ${ }^{16}$ tendo depois continuado a investigação, que iniciou no início do curso, até final de 1958. De regresso foi convidado para Assistente da Secção de Química da Faculdade de Ciências mas dedicava-se à investigação no IRC. Após o doutoramento em Química em 1966 pela Universidade de Lisboa voltou para Inglaterra, para a Universidade de Sheffield onde fez investigação com W. Bartley durante três anos. De regresso a Portugal foi supervisionar o grupo de Bioquímica do LFEN (Laboratório de Física e Energia Nuclear), depois LNETI (Laboratório Nacional de Engenharia e Tecnologia Industrial) e actualmente, INETI (Instituto Nacional de Engenharia e Tecnologia Industrial), onde se manteve até 1979 . altura em que ficou em regime de exclusividade como catedrático de Bioquímica da Faculdade de Ciências da Universidade de Lisboa. Desde 1975 até essa data foi professor convidado de Bioquímica (após K. Jacobsohn se jubilar) mas permanecendo no LNETI como responsável do departamento de Biologia. Renato Leal começou a sua vida de licenciado como Assistente de Química Inorgânica tendo-se depois interessado pela investigação bioquímica passando a ser orientado por Kurt Jacobsohn. No final dos anos cinquenta foi para Londres onde trabalhou durante um ano com A. Greebaun (University College). De regresso a Portugal doutorou-se pela Universidade de Lisboa em 1962, continuando a fazer a sua investigação no IRC até ao seu 
falecimento em 1976. Tornou-se catedrático de Química em 1970.

Estes três investigadores, que constituem a segunda geração de "bioquímicos", continuaram a investigação em Bioquímica, além de K. Jacobsohn, dando origem ao que se poderia considerar a terceira geração, constituída por cerca de uma dúzia de licenciados em Química da Faculdade de Ciências que na sua grande maioria, foram assistentes. Contudo só se doutoraram alguns deles que permaneceram ou se tornaram docentes da Faculdade (Luísa Neves e Cristina Santos). Jacques Calazans trabalhou com R. E. Pinto mas doutorou-se em Upsalla (Suécia) com Lövdin e M. Teresa Carreira teve como supervisor $\mathrm{J}$. Calazans. Também Ana Ponces Freire se doutorou com Carlos Manso (Faculdade de Medicina da Universidade de Lisboa) e Fátima Morais com Ana Ponces Freire. Também se doutoraram com Carlos Manso alguns engenheiros químicos mas só $\mathrm{M}$. Lurdes Mira faz parte desta terceira geração e é actualmente docente na Faculdade de Ciências. Consideramos como quarta geração os docentes doutorados a seguir a estes e como quinta geração, os licenciados em Bioquímica (F.C.U.L.) que se doutoraram ou que continuaram a investigação neste campo.

\section{PANORAMA ACTUAL \\ DA BIOQUÍMICA}

\section{DA FACULDADE DE CIÊNCIAS} DA UNIVERSIDADE DE LISBOA

Em 1982, foi criada a licenciatura em Bioquímica na Faculdade de
CiênciasXVII. Esta licenciatura teve uma aceitação difícil por parte do Ministério da Educação devido á diferença de critérios relativas às características da licenciatura, entre este e os docentes envolvidos. Desta situação resultou um atraso grande relativamente à primeira licenciatura em Bioquímica criada no nosso País, na Universidade de Coimbra. Pretendia a Faculdade de Ciências (U.L.) que a licenciatura tivesse quatro anos de escolaridade seguida de um ano de estágio de investigação científica e que não fosse apenas o somatório de um conjunto de disciplinas de Química e Biologia, como pretendia o Ministério. Além disso, entre outras coisas, pretendia-se que a licenciatura fosse dirigida essencialmente para formar investigadores, não excluindo a possibilidade dos licenciados pode-

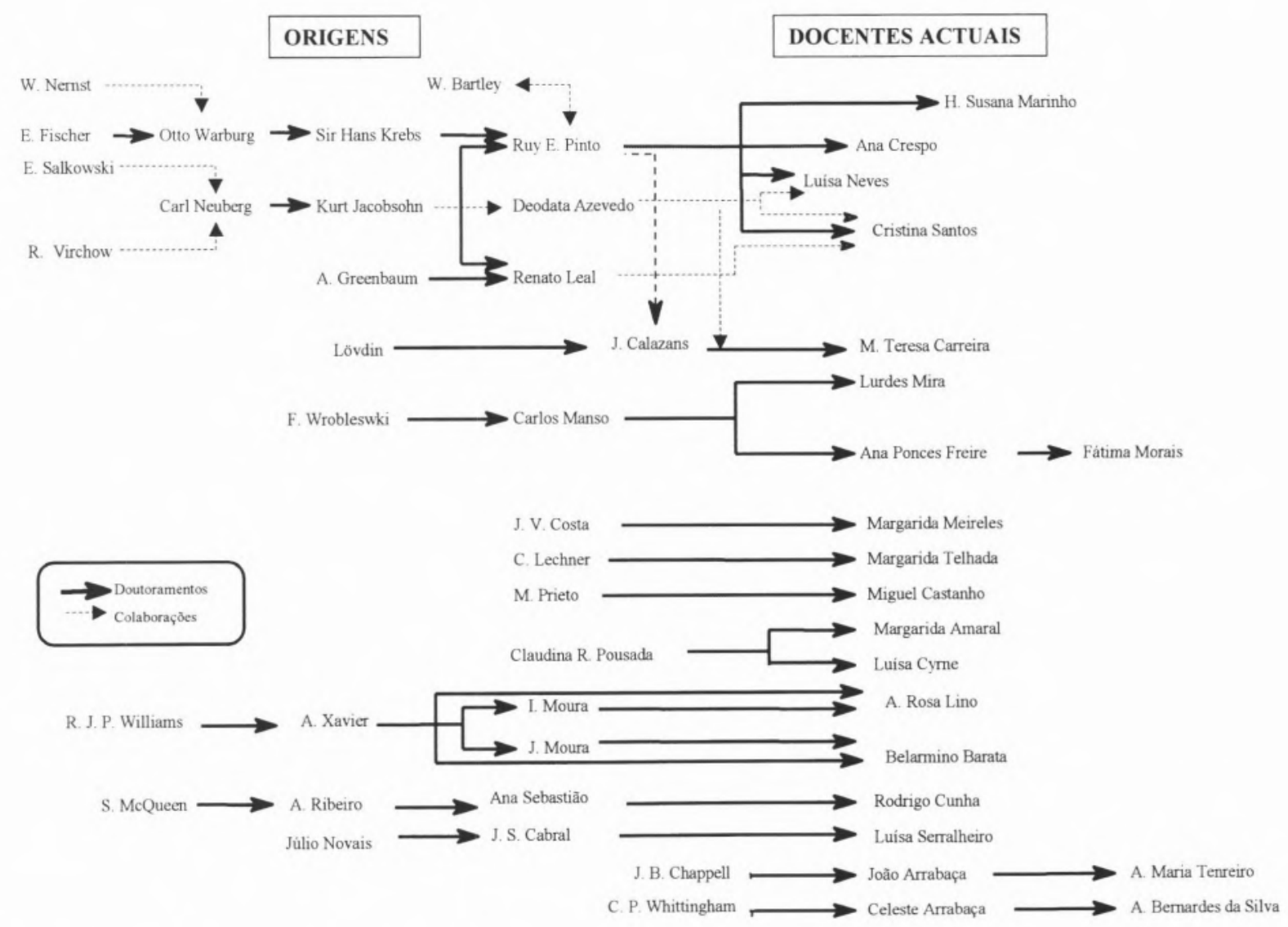

Fig. 1 - Docentes bioquímicos actuais da F.C.U.L. e suas origens científicas 
rem vir a ser docentes ou técnicos superiores. Deste processo de acordo difícil resultou então uma licenciatura com quatro anos, incluindo o estágio de investigação como uma disciplina do último semestre do curso. Esta situação resultou em prejuízo sobretudo dos primeiros licenciados pois na prática qualquer estágio de investigação foi concluído no mínimo após um ano de investigação. Só após a reforma de 1993 a situação se alterou e, de facto, actualmente, a licenciatura obedece a alguns requisitos pretendidos pela Faculdade de Ciências, como por exemplo, a escolaridade de quatro anos seguida de um ano de investigação.

Se se entender que uma escola é formada por todos aqueles que directa ou indirectamente tiveram influência, ou um papel decisivo, no rumo de qualquer carreira científica ou académica, embora se corra o risco de esquecer alguém, poder-se-á visualizar através das figuras apresentadas neste texto, uma tentativa de estabelecer essa rede de pessoas que naturalmente representam ideias, conceitos ou até metodologias de trabalho, que culminam nos actuais docentes da Faculdade ou seus investigadores que suportam e orientam a licenciatura de Bioquímica na F.C.U.L..

Na figura l procura-se relacionar as influências científicas marcantes expressas pelos cientistas que de alguma forma deram origem aos actuais docentes da F.C.U.L.. Os docentes da quarta e quinta geração foram-se doutorando em áreas especificas das quais a Faculdade carecia, recorrendo a cientistas do Instituto Gulbenkian de Ciência ou de outras Faculdades. Estes leccionaram pela primeira vez as disciplinas naquelas áreas e mantiveram-nas enquanto não houve docentes da Faculdade para o fazerXVIIIß.

Em síntese, a Universidade de Lisboa concedeu cerca de trinta doutoramentos entre graduados em Química e Bioquímica (figuras 2 e 3 ). Cerca de duas dúzias de licenciados em Bioquímica pela Faculdade de Ciências da U.L. obtiveram o grau de

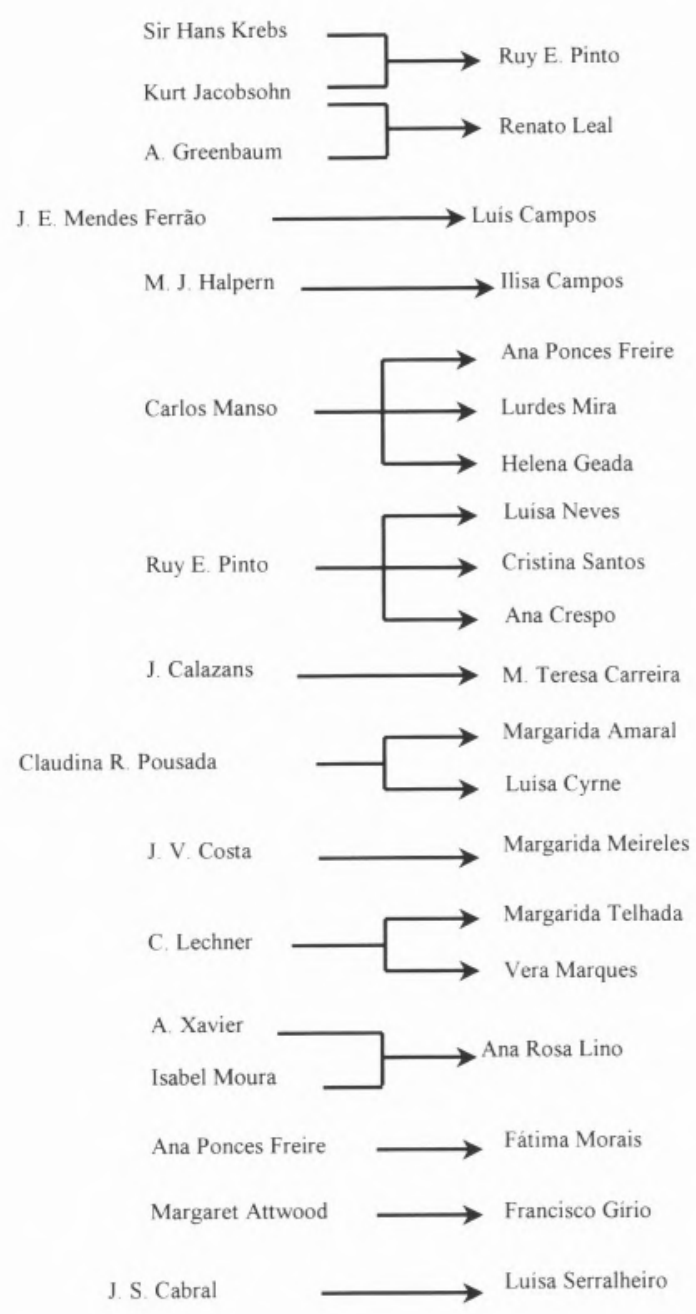

Fig. 2 - Doutores em Bioquímica (ou ciências afins) pela U.L. que não são licenciados em Bioquímica pela F.C.U.L.

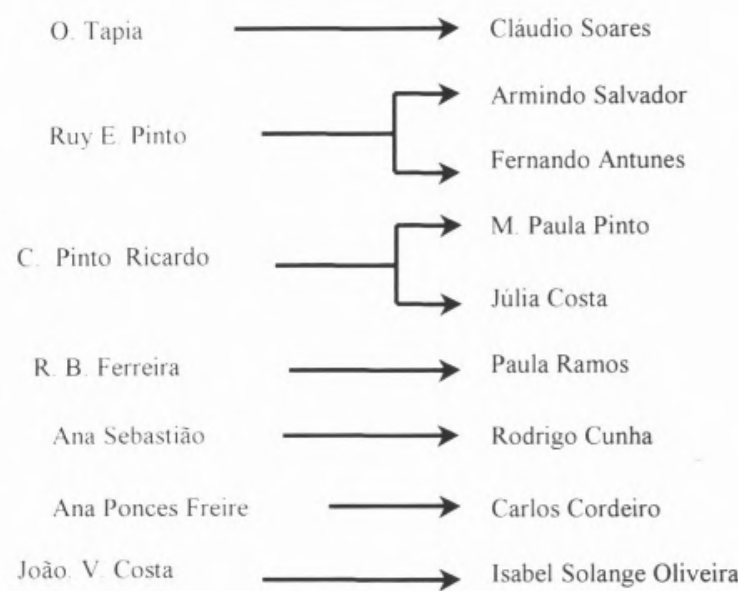

Fig. 3 - Doutoramentos de licenciados em Bioquímica da F.C.U.L. pela Universidade de Lisboa 


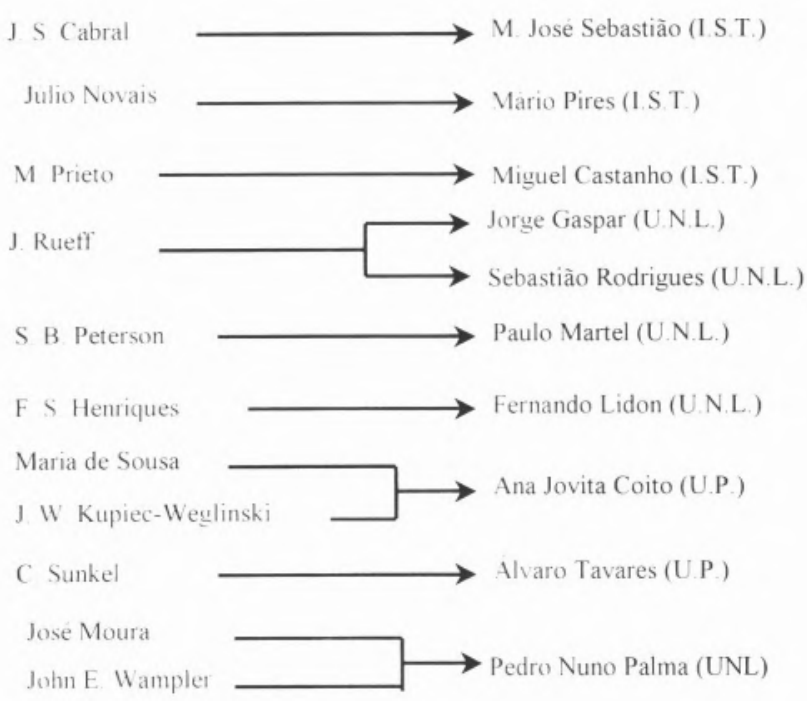

Fig. 4 - Doutoramentos em Bioquímica de licenciados em Bioquímica (F.C.U.L) por outras Universidades portuguesas

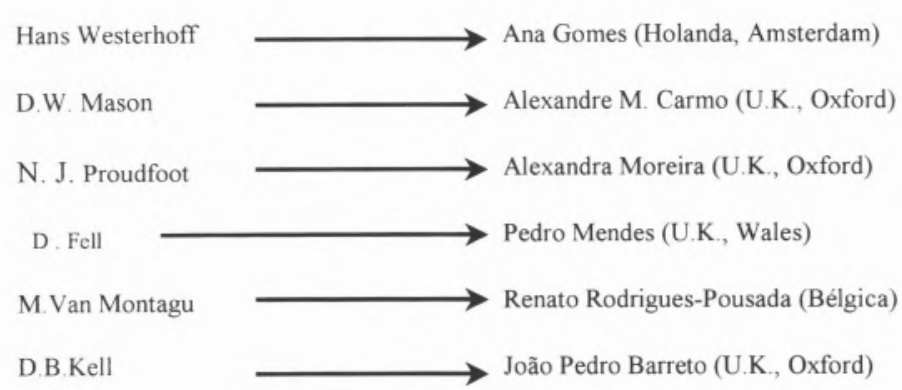

Fig. 5 - Doutoramentos em Bioquímica de licenciados em Bioquímica (F.C.U.L) no estrangeiro

\author{
Ana Jovita Coito \\ 1994 - The Upjohn Young Investigator Award, American Society of Transplant Physicians \\ 1995 - The ASTP Young Investigator Award, American Society of Transplant Physicians \\ 1996 - The ASTP Young Investigator Award, American Society of Transplant Physicians \\ Rodrigo Cunha
}

1994 - Menção Honrosa, Prémio da Boa Esperança

1995 - Prémio Gulbenkian de Estímulo à Investigação

Palmira Costa

1994 - Menção Honrosa, Prémio da Boa Esperança

Miguel Castanho

1996 - Prémio Gulbenkian de Estímulo à Investigação

Fig. 6 - Prémios atribuídos a licenciados em Bioquímica pela F.C.U.L.
Doutor em Portugal (figuras 3 e 4) nestes últimos anos, o que representa uma média de três por ano.

Por fim, parece-nos interessante referir os prémios atribuídos a licenciados em Bioquímica pela F.C.U.L. quer em Portugal quer no estrangeiro, (figura 6), pois julgamos que reflectirão, de alguma forma, o reconhecimento do mérito desses cientistas e, possivelmente também, das Escolas que os formaram.

NOTA: Palestra apresentada por Ruy E. Pinto, a 5 de Maio de 1997 na Reitoria da Universidade de Lisboa durante a Comemoração dos 15 anos da Licenciatura em Bioquímica da Faculdade de Ciências, (5-9 de Maio de 1997).

\section{AGRADECIMENTOS}

Gostaríamos de manifestar a nossa gratidão a todas as instituições e pessoas que colaboraram para que a exposição fosse possível. Pelo facto da exposição ter utilizado o espaço da Reitoria da U.L. agradecemos a adesão e cumplicidade do Senhor Reitor (Virgílio Meira Soares) para com o evento. Finalmente não poderíamos deixar de agradecer também à Dra. Eugénia Balsas e à Dra.Maria Leal pela disponibilidade e simpatia com que nos receberam e ajudaram.

\footnotetext{
* Professor Catedrático de Bioquímica (Jubilado) da Faculdade de Ciências, Universidade de Lisboa, Cidade Universitária, 1700 Lisboa. Director do Instituto de Investigação Científica Bento da Rocha Cabral, Calçada Bento da Rocha Cabral, 14, 1250 Lisboa.

**Assistente da Seç̧ão de História e Filosofia da Ciência, CICSA, Faculdade de Ciências e Tecnologia, U.N.L., 2825 Monte de Caparica.
}

\section{NOTAS E REFERÊNCIAS BIBLIOGRÁFICAS}

I Em 1903 existiam 2500 investigadores na Alemanha e publicaram 3000 artigos relacionados com os aspectos químicos das Ciências Biomédicas. Por outro lado, a Alemanha tinha 11 lugares académicos para os bioquímicos, a Áustria 8, os restantes países europeus 15 e a Inglaterra e os Estados Unidos tinham só 2. Ver em KoIher, R. E., From Medical Chemistry to Biochemistrythe making of a biomedical discipline, Cambridge University Press, Cambridge, 1982, pp.10. 
II Para mais pormenor consultar Lavoisier, A. ; Premier mémoire sur la respiration des animaux, Mémoire de I'Academie des Sciences, 1977, pp688-703 ou ainda em , Lavoisier, A. , Elements of Chemistry, in Enciclopaedia Britannica, Inc., xxvi ed., 1984, pp9-161.

III Entre o conjunto de contribuiçōes científicas de Lavoisier, as que maior relevância tiveram na Química Fisiológica, são a proposta do esquema geral da fermentação alcoólica, as teorias da respiração (oxidação lenta produzindo dióxido de carbono e água) e do calor animal, como resultado das oxidações biológicas.

IV Radot P. V., Oeuvre de Pasteur - Dissymetrie Moleculaire, Libraries de l'Academie de Médecine, Paris. 1922.

$\checkmark$ Foi Maria Manasseina que em 1872 demonstrou que as células de levedura não eram necessárias para que se desse a fermentação alcoólica. Poderia assim ser considerada o primeiro bioquímico ao contrário de $\mathrm{E}$. Büchner. Todavia, a sua descoberta passou despercebida de vido ao facto de se acreditar na época, no vitalismo. Em Lagnado, J. (1992), "Was the first biochemist a woman?", The Biochemist, 14, (5), 21-22.

VI Carl Alexander Neuberg foi discípulo de E. Salkowski e de R. Virchow.Em 1913 foi convidado para liderar o departamento de Bioquímica no recém criado Kaiser Wilhelm Institut fr Therapie cujo director era August von Wassermann. Entre 1920 e 1934 teve várias nomeações para o Prémio Nobel e em 1925, com a morte de August von Wassermann e dada a importância que o laboratório de Neuberg tinha no Kaiser Wilhelm Institut für Therapie, este passou a designar-se por Kaiser WiIhelm Institut für Biochemie, sendo Carl Neuberg o seu novo director. Em Amelie, L. Grauer, Enzymologia, Vol. XVIII, (1957) pp.1-2 ; Nord, F. F. "Obytuary", Advan. ces in Carbohydrate Chemistry and Biochemistry, Academic Press Publishers, Inc., New York, 1958 pp 1-7 Nord, F. F., Archives of Biochemistry and Biophysics. Vol. 69, Academic Press Inc., Publishers, New York, 1958, i. Foi membro de várias academias científicas, in cluindo Portugal. Em 1932 foi conferencista na Academia de Ciências de Lisboa sobre a degradação dos glícidos.

VII Consulte-se Krebs, H., Otto Warburg- Cell Phisiologist, biochemist and eccentric, Clarendon University Press, Oxford, 1981.

VIII Para consulta mais deltalhada, veja-se, Krebs, $\mathrm{H}$. Reminiscences and Reflections, Clarendon University Press, Oxford, 1981

Ix O seu grande mestre foi Mathias Duval. Iniciou a in vestigação numa das mais famosas escolas de investigação em histologia. Athias conheceu no laboratório de histologia de M. Duval alguns dos melhores histologistas franceses e tornou-se um homem de Ciência. A aprendeu a técnica histológica, sobretudo o difícil método de Golgi em que foi exímio e ao qual fez aperfeiçoamentos. Daí ter publicado vários trabalhos sobre a histogénese dos neurónios que lhe garantiram reconhecimento internacional.
X Em 1920 com Abel Salazar e Celestino da Costa, o seu primeiro assistente, Athias funda uma revista que permitia divulgar os trabalhos dos biologistas portugueses. Assim nasceram os Archives Portugaises des Sciences Biologiques. No mesmo ano Athias fundou também a Reuniāo Biológica de Lisboa, filial da Sociedade de Biologia de Paris, e dois anos depois tomou a designação de Sociedade Portuguesa de Biologia.

xI Também Porto e Coimbra desenvolveram um conjunto de iniciativas que culminaram na consolidação da Bioquímica em Portugal sobretudo a partir da década de 50-60. Em qualquer das Universidades, à semelhança de Lisboa, a Química Fisiológica, disciplina precursora da Bioquímica, começou a desenvolver-se en torno da Medicina. Todavia o Porto foi protagonista na consolidação da disciplina sobretudo a partir da Faculdade de Farmácia enquanto Coimbra o fez a partir da Faculdade de Ciências e Tecnologia.

XII $\mathrm{O}$ termo Bioquímica foi usado pela primeira vez por Felix Hoppe-Seyler em 1877 no preâmbulo do primeiro volume do Zeitschrift für Phvsiologische Chemie, o pri meiro periódico vocacionado para a divulgação da Quí mica Fisiológica na Alemanha e que ele próprio editou. Em Hoppe-Seyler, Z. physiol. Chem., 1, I, 1877-8.

XIII Ferreira de Mira foi escolhido por Bento da Rocha Cabral por vontade testamentária, para fundador e director do IRC. A esolha recaíu sobre Ferreira de Mira porque este escrevia artigos de divulgação científica, sobre cultura e ensino publicados no periódico, a lucta (lido por Bento da Rocha Cabral no Brasil) onde defendia insistentemente a importância que os Institutos independentes e financiados por benemerência tinham para o desenvolvimento científico, como complemento do papel do estado. Sendo Bento da Rocha Cabral un milionário, resolveu deixar grande parte da sua fortun para que em Portugal se edificasse um Instituto de Investigação à semelhança dos Institutos Rockefeller e Carnegie, nos Estados Unidos, embora de dimensões diferentes, oIRC.

XIV Não sendo possivel criar nas instalações do instituto, um laboratório especial para cada ramo das ciências biológicas, foram instalados laboratórios apenas em quatro secçōes: Fisiologia, Histologia, Química Biológica e Bacteriologia. Com a liderança de K. P. Jacobsohn a seç̧ão de Química Biológica passou a designar-se laboratório de Bioquímica.

XV Durante cerca de cinquenta anos de vida activa de investigação K. P. Jacobsohn publicou cerca de duzentos e cinquenta trabalhos. Foi Professor Catedrático em 1956 e Vice-Reitor da U.L. em 1970

XVI Ruy E. Pinto foi colega, em Oxford, de Manuel Sobrinho Simões, doutorado em Medicina pela Universidade do Porto. Ambos integraram o primeiro curso experimental de Bioquímica organizado por H.A.Krebs que reunia seis cientistas de várias partes do Mundo, sendo metade deles já doutorados.

xVII Dec. Lei $\mathrm{n}^{\circ}$ 125/82; Portaria n² 1022/82

XVIII Aproveitamos a oportunidade para agradecer a todos os professores convidados que durante alguns anos foram responsáveis pela leccionação das disciplinas da licenciatura de Bioquímica e/ou pela formação de doutorados.

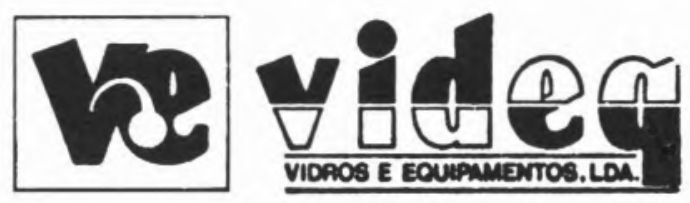

\author{
Equipamento de Laboratório \\ Balanças - Centrifugas - Aparelhos de $\mathrm{pH}$ - Tituladores \\ Condutímetros - Agitadores - Espectrofotómetros \\ Microscópios - etc.
}

Vidros e Plásticos de Laboratório Distribuidores NORMAX

Material Didáctico

Ensino Secundário e Superior

Representantes exclusivos SISTEDUC - Sistemas Educativos S.A.

Rua Soeiro Pereira Gomes, 15 r/c Frente

Bom Sucesso - 2615 Alverca

Telefs. (01) 95704 20/1/2 - Fax (351-1-957 04 23) - Portugal 